\title{
Laporan kasus berbasis bukti Perbandingan Efektifitas dan Keamanan Midazolam Buccal dengan Diazepam Intravena dalam Tata Laksana Kejang Akut pada Anak
}

Achmad Rafli, Setyo Handryastuti

Departemen Ilmu Kesehatan Anak Fakultas Kedokteran Universitas Indonesia/RS Dr. Cipto Mangunkusumo, Jakarta

Latar belakang. Literatur terbaru menunjukkan bahwa midazolam yang diberikan secara non-intravena memungkinkan untuk pemberian yang lebih cepat, sama efektif, dan aman bila dibandingkan dengan diazepam IV dalam mengatasi kejang akut pada anak.

Tujuan. Mengetahui efektivitas dan keamanan midazolam buccal dibandingkan dengan diazepam terutama IV sebagai terapi kejang akut pada anak.

Metode. Penelusuran pustaka database elektronik yaitu Pubmed, Cochrane, MEDLINE, Embase dan Google Scholar.

Hasil. Telaah sistematis dan meta-analisis menunjukkan menunjukkan bahwa angka kejadian berhentinya kejang dalam 10 menit pada subyek yang diberikan midazolam buccal sama dengan yang diberikan diazepam IV dengan relative risk (RR) 0,92, 95\% interval kepercayaan (IK) 0,81-1,05; waktu yang dibutuhkan untuk mengontrol episode kejang setelah pemberian obat anti-kejang pada subyek yang diberikan midazolam buccal lebih tinggi dengan mean difference 0,63; 95\% IK 0,38-0,89; efek samping signifikan yang timbul setelah pemberian diazepam IV lebih tinggi, yaitu apnea pada 4/60 subyek. Midazolam buccal memiliki efektivitas dan keamanan yang sama dengan diazepam IV dalam mengatasi kejang. Kesimpulan. Midazolam buccal memiliki efektivitas dan keamanan yang sama dengan diazepam IV dalam mengatasi kejang. Berdasarkan penelitian ilmiah yang telah dipaparkan, efek samping midazolam buccal seperti depresi napas maupun hipotensi jarang terjadi bila dibandingkan dengan diazepam IV. Sari Pediatri 2017;19(4):231-6

Kata kunci: kejang, midazolam, diazepam

\section{Comparative Effectiveness and Security of Midazolam Buccal with Intravenous Diazepam in the Management of Acute Attack on Children}

Achmad Rafli, Setyo Handryastuti

Background. Prompt treatment of status epilepticus is associated with better outcomes. Rectal diazepam and nonintravenous midazolam are often used in the treatment of early SE instead of intravenous applications.

Objective. To determine if nonintravenous midazolam is as effective and safe as IV diazepam, in terminating acute seizures in children.

Methods. The literature search using electronic database: Pubmed, Cochrane, MEDLINE, Embase and Google Scholar. Results. Systematic review and meta-analysis showed the time to seizure cessation in 10 minutes after drug administration was lower in the intravenous group compare to midazolam buccal, with relative risk (RR) 0.92 , 95\% Confidence interval (CI) 0.81-1.05; time for controlling seizure episode to subjects with buccal midazolam was longer with mean difference 0.63; 95\% CI 0.38-0.89; Significant adverse effects were infrequently reported and when present, were similar in both the groups.

Conclusion. Buccal midazolam is as effective and safe as intravenous diazepam in terminating seizure in children. Midazolam also showed fewer side effects compare to diazepam. Sari Pediatri 2017;19(4):231-6

Keywords: seizure, midazolam, diazepam

Alamat korespondensi: Dr. Achmad Rafli. Departemen Ilmu Kesehatan Anak Fakultas Kedokteran Universitas Indonesia/RS Dr. Cipto Mangunkusumo, Jakarta. Email: achmad.rafli@gmail.com 
K

ejang, baik disertai atau tanpa demam, merupakan salah satu kegawatdaruratan di bidang neurologi dan masih menjadi masalah gering timbul pada anak. Bila kejang berkembang menjadi status epileptikus, yaitu kejang yang berlangsung selama 30 menit atau kejang berulang selama lebih dari 30 menit tanpa pemulihan kesadaran di antara 2 serangan kejang, dapat menyebabkan morbiditas, seperti kerusakan otak permanen dan mortalitas. ${ }^{1,2}$ Penanganan yang cepat dan penggunaan obat yang tepat merupakan salah satu kunci keberhasilan menghentikan kejang, menentukan faktor prognostik, dan mencegah terjadinya kejang berulang. Pengobatan kejang yang sampai saat ini dianggap ideal adalah obat yang mudah diberikan, aman, efektif, dan memiliki efek anti-kejang yang cukup baik.,

Beberapa obat anti-kejang yang tersedia saat ini, seperti golongan benzodiazepin (diazepam, midazolam, dan lorazepam), feniotin, dan fenobarbital masih digunakan sebagai terapi lini pertama pada tata laksana kejang akut pada anak. ${ }^{5}$ Diazepam dapat diberikan, baik secara intravena (IV), rektal, atau intramuskular (IM). ${ }^{6}$ Pengobatan dengan rute tersebut dapat menyebabkan pemberian obat anti-kejang terlambat, seperti pemberian secara intramuskular/rektal karena pasien harus melepaskan pakaian dan dalam posisi yang benar; pemberian intravena memerlukan akses vena yang baik sehingga sulit. Di sisi lain, midazolam dapat diberikan, baik secara intravena, buccal, maupun nasal.

Beberapa literatur terbaru menunjukkan bahwa midazolam yang diberikan secara non-intravena memungkinkan untuk pemberian yang lebih cepat, sama efektif dan aman bila dibandingkan dengan diazepam IV dalam mengatasi kejang akut pada anak. ${ }^{7,8}$ $\mathrm{Hal}$ ini terutama pada penggunaan midazolam buccal yang dinyatakan dalam beberapa penelitian sama efektif dengan diazepam rektal dalam mengontrol kejang. Namun, protokol penggunaan midazolam buccal sampai saat ini masih belum jelas. ${ }^{9,10}$

Saat ini, pemberian midazolam secara buccal telah dimasukkan ke dalam salah satu obat anti-kejang pada algoritme tata laksana kejang pada Rekomendasi Penatalaksanaan Status Epileptikus Ikatan Dokter Anak Indonesia tahun 2016, ${ }^{11}$ tetapi dalam praktiknya masih belum digunakan terutama di Unit Gawat Darurat (UGD). Penelitian berbasis bukti ini ditujukan untuk membahas efektivitas dan keamanan midazolam buccal dibandingkan dengan diazepam terutama IV sebagai terapi kejang akut pada anak sehingga dapat diterapkan pada praktik sehari-hari.

\section{Kasus}

Seorang anak laki-laki berusia 2 tahun 7 bulan, berat badan 9,3 kg datang dengan keluhan kejang berulang yang terjadi satu hari sebelum masuk rumah sakit (SMRS). Saat kejang, tubuh pasien menjadi kaku dan mata pasien mendelik ke atas. Kejang terjadi selama kurang dari lima menit dan berulang lebih dari 10 kali. Jarak antara kejang adalah sekitar dua sampai tiga jam. Saat kejang pasien tidak sadar dan setelah kejang pasien rewel, menangis, tetapi masih kontak, lalu tertidur, dan dapat berkomunikasi kembali seperti semula. Kejang yang dialami pasien tanpa disertai demam dan tidak dipengaruhi waktu, tetapi biasanya dipicu oleh rasa lelah seperti setelah bermain. Pasien tidak memiliki riwayat kejang, baik dengan/tanpa demam sebelumnya, trauma, kejang lebih dari 30 menit, atau tidak bisa dibangunkan di antara terjadinya kejang sebelumnya. Riwayat keluarga dengan keluhan yang sama, gangguan pertumbuhan, dan perkembangan disangkal. Pasien didiagnosis sebagai epilepsi umum tonik idiopatik.

Setelah dilakukan stabilisasi baik pada jalan napas, pernapasan, dan sirkulasi, tata laksana kejang akut pada pasien ini di UGD adalah pemberian diazepam 5 mg secara rektal dan karena kejang masih berlanjut dalam jarak 10 menit, pasien diberikan diazepam $5 \mathrm{mg}$ IV $(0.5 \mathrm{mg} / \mathrm{kg} / \mathrm{kali})$. Pemberian obat kejang sempat tertunda karena sulitnya akses IV pada pasien. Selama observasi di UGD terjadi kejang kembali sehingga diberikan fenitoin (loading dose) $20 \mathrm{mg} / \mathrm{kgBB} / \mathrm{kali}$, yaitu $180 \mathrm{mg}$ dalam $10 \mathrm{~mL} \mathrm{NaCl}$ 0,9\% dan diberikan dalam 10 menit IV dilanjutkan dengan fenitoin (maintenance dose) $10 \mathrm{mg} / \mathrm{kgBB} / \mathrm{hari}$, yaitu $25 \mathrm{mg} \mathrm{IV}$ tiap 12 jam yang diencerkan dalam $5 \mathrm{~mL} \mathrm{NaCl} 0.9$ $\%$ dan diberikan dalam 5 menit.

Kasus di atas menimbulkan pertanyaan klinis sebagai berikut: Masalah yang dihadapi adalah pemberian obat anti konvulsan sempat tertunda karena akses IV yang cukup sulit dan bagaimana efektivitas dan keamanan midazolam buccal bila dibandingkan dengan diazepam IV pada tata laksana kejang akut pada anak?

\section{Metode}

Untuk menjawab masalah di atas, prosedur pencarian pustaka dilakukan dengan menelusuri literatur secara online, menggunakan instrumen pencari Pubmed 
dan Cochrane. Kata kunci yang digunakan adalah "midazolam","buccal", "seizure", "diazepam", "children", "efficacy" dengan menggunakan batasan: bahasa pengantar adalah bahasa Inggris, publikasi literatur dalam rentang waktu 10 tahun terakhir, serta penelitian dengan penelitian uji coba klinis, telaah sistematik atau meta-analisis. Berdasarkan metode penelusuran dengan kriteria di atas, didapatkan hanya terdapat 2 artikel yang dianggap relevan dengan masalah di atas. Levels of evidence ditentukan berdasarkan klasifikasi yang dikeluarkan oleh Oxford Centre for Evidence-Based Medicine. ${ }^{12}$ Artikel yang terpilih adalah penelitian telaah sistematik/meta-analisis.

\section{Hasil penelusuran literatur}

\section{Telaah sistematis dan meta-analisis (level of evidenceI)}

Jain $\mathrm{dkk}^{13}$ melakukan telaah sistematis dan metaanalisis pada tahun 2016 untuk membandingkan efektifitas dan keamanan obat anti-epilepsi pada pasien dengan kejang bila akses IV sulit didapatkan. Penelitian yang diinklusi dalam telaah sistematis dan meta-analisis ini adalah uji acak dan quasi-acak terkontrol dengan blind melalui penelusuran MEDLINE, Embase (1980 sampai dengan Mei 2015); Cochrane Central dan Google Scholar (sampai dengan Mei 2015). Subyek pada penelitian ini adalah anak berusia di atas 1 bulan dengan kejang akut baik yang baru pertama kali kejang atau telah didiagnosis epilepsi sebelumnya.

Intervesi penelitian ini adalah pemberian dua macam obat anti-kejang baik secara IV maupun non-IV (rektal, intranasal, buccal, sublingual, dan intramuskular). Obat yang digunakan adalah midazolam, diazepam, lorazepam, dan paraldehid. Luaran primer yang dinilai adalah jumlah subyek dengan kejang berhenti dalam waktu 10 menit setelah obat anti-kejang diberikan; luaran sekunder, yaitu waktu yang dibutuhkan untuk berhentinya kejang dari waktu subyek masuk rumah sakit/klinik, hingga episode kejang terkontrol setelah obat anti-kejang diberikan, dan angka kejadian efek samping pemberian obat anti-kejang (depresi napas dan hipotensi).

Data pada studi ini diambil dan diolah oleh 2 peninjau mandiri dan ditemukan 2 penelitian uji klinis yang membandingkan efektivitas dan keamanan midazolam buccal dengan diazepam IV. Hasil telaah sistematis menunjukkan bahwa angka kejadian berhentinya kejang dalam 10 menit pada subyek yang diberikan midazolam buccal sama dengan yang diberikan diazepam IV dengan relative risk (RR) 0.92, 95\% interval kepercayaan (IK) 0,81-1,05; waktu yang dibutuhkan untuk mengontrol episode kejang setelah pemberian obat anti-kejang pada subyek yang diberikan midazolam buccal lebih tinggi dengan mean difference 0,63; 95\% IK 0,38-0,89; efek samping signifikan yang timbul setelah pemberian diazepam IV lebih tinggi, yaitu apnea pada 4/60 subyek.

Terdapat 2 uji klinis pada telaah sistematis tersebut yang meneliti efektifitas dan keamanan midazolam buccal bila dibandingkan dengan diazepam IV, yaitu penelitian oleh Talukdar dan Chakrabarty, ${ }^{14}$ Tonekaboni dkk. ${ }^{15}$

Talukdar dan Chakrabarty ${ }^{14}$ melakukan uji klinis acak terkontrol pada 120 anak yang datang ke UGD dengan keluhan kejang dan diberikan terapi dengan midazolam buccal $(0,2 \mathrm{mg} / \mathrm{kgBB} / \mathrm{kali})$ atau diazepam IV $(0,3 \mathrm{mg} / \mathrm{kgBB} / \mathrm{kali})$. Angka kejadian terkontrolnya kejang dalam 5 menit adalah $85 \%$ dan $93,3 \%$ pada kelompok subyek yang diberikan midazolam buccal dan diazepam IV secara berurutan, tetapi tidak signifikan secara statistik $(\mathrm{p}=0,142)$. Waktu yang dibutuhkan untuk mengontrol terjadinya kejang kembali setelah diberikan obat anti-kejang lebih cepat pada kelompok subyek yang diberikan midazolam buccal ( $\mathrm{p}=0,004)$. Hal ini disebabkan karena dibutuhkan waktu yang cukup lama dalam mempersiapkan akses IV. Efek samping serius akibat pemberian obat tidak ditemukan pada penelitian ini. Kesimpulan penelitian ini adalah midazolam buccal dapat digunakan sebagai obat antikejang alternatif bila akses IV tidak tersedia.

Tonekaboni $\mathrm{dkk}^{15}$ melakukan uji klinis acak terkontrol pada 92 subyek anak berusia 6 bulan-14 tahun dengan kejang yang diberikan midazolam buccal (32 subyek) atau diazepam IV (60 subyek). Dosis midazolam buccalyang diberikan adalah $2,5 \mathrm{mg}$ (anak 6-12 bulan), $5 \mathrm{mg}$ (1-4 tahun), 7,5 mg (5-9 tahun), dan $10 \mathrm{mg}$ (10 tahun ke atas) per kali; dosis diazepam IV adalah $0,3 \mathrm{mg} / \mathrm{kg} / \mathrm{kali}$. Angka kejadian terkontrolnya kejang dalam waktu 10 menit adalah 68,8\% dan 70\% pada kelompok subyek yang diberikan midazolam buccal dan diazepam IV secara berurutan. Hasil ini tidak signifikan secara statistik $(\mathrm{p}=0,9)$. Rata-rata waktu yang dibutuhkan untuk mengontrol episode kejang setelah diberikan obat anti-kejang tidak signifikan secara statistik $(\mathrm{p}=0,09)$. Pada penelitian ini tidak 
ditemukan efek samping yang serius, seperti depresi napas dan hipotensi pada kedua kelompok subyek. Kesimpulan penelitian ini adalah midazolam buccal memiliki efektivitas dan keamanan yang sama dengan diazepam IV dalam mengatasi kejang.

\section{Telaah sistematis dan meta-analisis (level of evidenceI)}

Brigo dkk ${ }^{16}$ pada tahun 2015 melakukan telaah sistematis dan meta-analisis yang membandingkan midazolam non-IV (intranasal, buccal, intramuskular) dengan diazepam IV atau rektal untuk penanganan status epileptikus pada anak dan dewasa. Inklusi penelitian ini adalah penelitian dengan uji acak terkontrol, baik blind maupun tidak, dengan subyek adalah semua pasien dengan segala umur yang datang ke UGD dengan keluhan kejang, baik yang telah terdiagnosis status epileptikus, kejang lebih dari 5 menit, atau kejang saat tiba di UGD.

Luaran yang dinilai adalah efektivitas (episode status epileptikus yang dapat dihentikan dalam 15 menit setelah pemberian obat/pelayanan medis gawat darurat diberikan, waktu subyek sampai di UGD sampai obat anti-kejang diberikan, waktu kejang berhenti setelah diberikan obat anti-kejang, dan waktu subyek sampai UGD sampai kejang berhenti). Sementara itu, luaran keamanan adalah jumlah subyek yang mengalami efek samping obat anti-kejang yang serius (depresi napas atau hipotensi). Dua peninjau mandiri mengolah dan menganalisis data yang didapatkan. Dari hasil analisis didapatkan 2 penelitian yang sama dengan yang ditelaah oleh Jain $\mathrm{dkk}^{13}$ untuk perbandingan efektivitas dan keamanan midazolam buccal dengan diazepam IV, yaitu Talukdar dan Chakrabarty, ${ }^{14}$ Tonekaboni dkk. ${ }^{15}$

Telaah yang dilakukan Brigo $\mathrm{dkk}^{16}$ yang mencakup berbagai rute pemberian midazolam, selain rute IV dibandingkan dengan diazepam IV atau rektal. Telaah ini menemukan kegagalan untuk menemukan perbedaan yang signifikan dalam terminologi berhentinya kejang (seizure cessation) dan kejadian efek samping obat anti-kejang. Hal tersebut disebabkan oleh beberapa hal, yaitu telaah sistematis yang dilakukan masih mungkin tidak termasuk penelitian yang tidak dipublikasi, perbandingan meta-analisis yang dilakukan tidak menggunakan fixed-effect model, luaran efektifitas berbeda (berhentinya kejang dalam 15 menit setelah obat diberikan), dsb.

\section{Pembahasan}

Benzodiazepin telah digunakan dalam tata laksana kejang akut dan epilepsi sejak tahun 1960 dan sampai saat ini masih merupakan obat pilihan pertama untuk status epileptikus dan kejang berkepanjangan baik untuk anak maupun dewasa. Obat yang termasuk golongan ini seperti, diazepam, lorazepam, dan midazolam memberikan efek neurofarmakologi, yaitu sedasi, relaksasi otot, dan aksi anti-kejang. ${ }^{17}$

Salah satu obat golongan benzodiazepin, yaitu diazepam (khususnya yang diberikan secara rektal) merupakan obat yang paling sering dipakai untuk tata laksana kejang pada anak, akses IV tidak didapatkan/di luar rumah sakit. Walaupun demikian, perkembangan di dunia saat ini menunjukkan tren bahwa cukup banyak penggunaan golongan benzodiazepin lain, yaitu midazolam buccal sebagai obat anti-kejang. ${ }^{18,19}$ Hal yang mendasari perkembangan ini adalah pemberian diazepam rektal dianggap kurang praktis, menimbulkan ketidaknyamanan pada pasien, terutama remaja dan dewasa terutama berhubungan dengan sexual abuse sehingga dalam waktu 10 tahun di Inggris midazolam buccal menjadi pilihan. ${ }^{17}$

Midazolam, yang merupakan anti-kejang yang poten, biasanya diberikan melalui rute IV atau IM. Benzodiazepin yang mengandung cincin imidazol ini memiliki sifat larut dalam air, cepat diabsorbsi melalui rektal, nasal, dan mukosa buccal; juga lipofilik pada keadaan $\mathrm{pH}$ fisiologis sehingga memfasilitasi efek yang cepat pada sistem saraf pusat. Mekanisme kerja midazolam dalam mengatasi kejang adalah berikatan dengan reseptor benzodiazepin stereospesifik pada saraf gamma-aminobutyric acid (GABA) pada sistem saraf pusat (sistem limbik dan formasio retikularis). Ikatan ini menimbulkan efek inhibisi pada pengeluaran neurotransmiter dan bila diaktivasi oleh GABA, reseptor GABA membuat ion klorida masuk sehingga membran saraf hiperpolarisasi. Benzodiazepin tidak berikatan pada resepto GABA yang sama sehingga menimbulkan modulasi reseptor yang menyebabkan meningkatnya afinitas terhadap GABA. Hal ini meningkatkan frekuensi terbukanya kanal ion klorida sehingga memperkuat efek inhibisi. ${ }^{17}$

Pemberian obat secara buccal memiliki keunikan tersendiri, yaitu mukosa buccal memiliki luas permukaan yang cukup luas $(50 \mathrm{~cm})$, vaskularisasi yang baik untuk mencapai sirkulasi sistemik sehingga tidak 
melewati metabolisme di hati, memiliki ekspresi enzim dengan derajat yang rendah sehingga lebih banyak obat yang diabsorbsi daripada yang didegradasi. ${ }^{20}$ Beberapa penelitian menunjukkan absorbsi obat melalui buccal adalah dengan mekanisme difusi pasif pada membran lemak. ${ }^{21}$ Studi yang dilakukan oleh Scott $\mathrm{dkk}^{22}$ menunjukkan bahwa midazolam yang diberikan melalui buccal sama efektifnya dengan rektal dalam mengatasi kejang akut.

Bila diberikan secara buccal, midazolam dapat diberikan baik dalam sediaan IV/IM, diambil sesuai dosis yang diperlukan dengan menggunakan spuit 1 $\mathrm{mL}$ yang telah dibuang jarumnya, dan teteskan pada buccal kanan, selama 1 menit. Dosis midazolam buccal berdasarkan kelompok usia adalah 2,5 mg (usia 6-12 bulan), $5 \mathrm{mg}$ (usia 1-5 tahun), 7,5 mg (usia 5-9 tahun), dan $10 \mathrm{mg}$ (usia $\geq 10$ tahun). ${ }^{11,17}$

Hal yang menjadi perhatian serius dalam pemberian obat golongan benzodiazepin khususnya midazolam buccal pada anak adalah risiko depresi pernapasan dan kardiovaskular, khususnya bila diberikan di luar rumah sakit. Depresi napas sebagai efek samping midazolam buccal dilaporkan dalam beberapa penelitian dengan angka kejadian $0,6 \%-5 \% \cdot{ }^{23} \mathrm{Di}$ sisi lain, studi yang dilakukan Kutlu dkk ${ }^{24}$ dan Melendez $\mathrm{dkk}^{25}$ menunjukkan hasil yang berbeda, yaitu tidak ditemukannya gangguan kardiorespirasi pada anak yang diberikan midazolam buccal.

Aspirasi juga merupakan masalah yang banyak ditelaah pada pemberian midazolam buccal pada anak yang sedang dalam keadaan kejang. Volume obat yang diberikan sangat kecil dan kemungkinan dapat berlebihan dengan tercampurnya saliva selama kejang. Hal ini dianggap tidak membahayakan bagi anak. ${ }^{17}$

Penelitian yang meneliti perbandingan efektifitas dan keamanan midazolam buccal dengan diazepam IV beberapa dekade terakhir sangat sedikit. Penelitian oleh Jain $\mathrm{dkk}^{13}$ membandingkan efektifitas dan keamanan obat anti-epilepsi pada pasien dengan kejang bila tidak terdapat akses IV. Kesimpulan penelitian ini adalah midazolam buccal dapat digunakan sebagai obat antikejang alternatif bila akses IV tidak tersedia; memiliki efektivitas dan keamanan yang sama dengan diazepam IV dalam mengatasi kejang pada anak. Hasil ini juga sejalan dengan penelitian yang dilakukan Brigo dkk. ${ }^{16}$

Kasus anak laki-laki usia 2 tahun 7 bulan dengan diagnosis epilepsi umum tonik idiopatik dalam keadaan kejang akut. Masalah yang dihadapi adalah sempat tertunda pemberian obat diazepam IV karena akses IV yang cukup sulit. Terdapat dua penelitian yang relevan untuk menjawab pertanyaan klinis mengenai efektifitas dan keamanan midazolam buccal dibandingkan dengan diazepam IV, yaitu Jain dkk ${ }^{13}$ dan Brigo dkk. ${ }^{16}$ Kedua penelitian tersebut menunjukkan midazolam buccal memiliki efektivitas dan keamanan yang sama dengan diazepam IV dalam mengatasi kejang pada anak. Tidak ada satu pun penelitian menunjukkan hasil yang signifikan mengenai efek samping midazolam buccal seperti depresi napas maupun hipotensi.

\section{Kesimpulan}

Midazolam buccal memiliki efektivitas dan keamanan yang sama dengan diazepam IV dalam mengatasi kejang. Berdasarkan penelitian ilmiah yang telah dipaparkan, efek samping midazolam buccal seperti depresi napas maupun hipotensi jarang terjadi bila dibandingkan dengan diazepam IV.

\section{Saran}

Walaupun midazolam buccal memiliki efektivitas dan keamanan yang sama dengan diazepam IV, tidak bersifat invasif, dan efek samping yang minimal, tetapi penggunaan obat tersebut masih terbatas dan perlunya sosialisasi protokol dalam hal dosis serta cara pemberian.

\section{Daftar pustaka}

1. Bhattacharyya M, Kalra V, Gulati S. Intranasal midazolam vs rectal diazepam in acute childhood seizures. Pediatr Neurol 2006;34:355-9.

2. Berg AT, Shinnar S, Testa FM, Levy SR, Frobish D, Smith SN, $\mathrm{dkk}$. Status epilepticus after the initial diagnosis of epilepsy in children. Neurology 2004;63:1027-34.

3. Prasad M, Krishnan PR, Sequeira R, Al-Roomi K. Anticonvulsant therapy for status epilepticus. Cochrane Database Syst Rev 2014;9:CD003723.

4. Scott RC, Besag FM, Neville BG. Buccal midazolam and rectal diazepam for treatment of prolonged seizures in childhood and adolescence: a randomised trial. Lancet 1999;353:623-6.

5. De Haan GJ, van der Geest P, Doelman G, Bertram E, Edelbroek P. A comparison of midazolam nasal spray and diazepam rectal solution for the residential treatment of seizure 
Achmad Rafli dkk: Perbandingan efektifitas dan keamanan midazolam buccal dengan diazepam intravena dalam tata laksana kejang akut

exacerbations. Epilepsia 2010;51:478-82.

6. Holsti M, Dudley N, Schunk J, Adelgais K, Greenberg R, Olsen $\mathrm{C}$, dkk. Intranasal midazolam vs rectal diazepam for the home treatment of acute seizures in pediatric patients with epilepsy. Arch Pediatr Adolesc Med 2010;164:747-53.

7. Avadzadeh M, Sheibani K, Hashemieh M, Saneifard H. Intranasal midazolam compared with intravenous diazepam in patients suffering from acute seizure: a randomized clinical trial. Iran J Pediatr 2012;22:1-8.

8. Klimach VJ. The community use of rescue medication for prolonged epileptic seizures in children. Seizure 2009;18:3436.

9. Brigo F. New anti-epileptic drugs: overcoming the limits of randomised controlled trials. Int J Evid Based Health 2011;9:440-3.

10. Brigo F, Igwe SC, Nardone R, Tezzon F, Bongiovanni LG, Trinka E. A common reference-based indirect comparison meta-analysis of intravenous valproate versus intravenous phenobarbitone for convulsive status epilepticus. Epileptic Disord 2013;15:314-23.

11. Ismael S, Hardiono DP, Dwi PW, Irawan M, Setyo H. Rekomendasi penatalaksanaan status epileptikus. Jakarta: Ikatan Dokter Anak Indonesia; 2016.h.1-7.

12. Oxford Centre of Evidence-Based Medicine. Levels of Evidence. 2011. Diakses pada tanggal 20 September 2016. Diunduh dari: http://www.cebm.net/wp-content/ uploads/2014/06/CEBM-Levels-of-Evidence-2.1.pdf2011.

13. Jain P, Suvasini S, Tarun D, Corrado B, Rshmi RD, Satinder A. Efficacy and safety of anti-epileptic drugs in patients with active convulsive seizures when no IV access is available: systematic review and meta-analysis. Epilepsy Res 2016;122:47-55.

14. Talukdar B, Chakrabarty B. Efficacy of buccal midazolam compared to intravenous diazepam in controlling convulsions in children: a randomized controlled trial. Brain Dev 2009;31:744-9.

15. Tonekaboni SH, Shamsabadi FM, Anvari SS, Mazrooei
A, Ghofrani M. A comparison of buccal midazolam and intravenous diazepam for the acute treatment of seizures in children. Iran J Pediatr 2012;22:303-8.

16. Brigo F, Raffaele N, Frediano T, Eugen T. Nonintravenous midazolam versus intravenous or rectal diazepam for the treatment of early status epilepticus: a systematic review with meta-analysis. Epilepsy Behav 2015;49:325-36.

17. Anderson M. Buccal midazolam for pediatric convulsive seizures: efficacy, safety, and patient acceptability. Patient preference and adherence 2013;7:27-34.

18. Ilbergleit R, Lowenstein D, Durkalski V, Conwit R. Lessons from the RAMPART study and which is the best route of administration of benzodiazepines in status epilepticus. Epilepsia 2013;54:74-7.

19. Sanchez CR, Camino R, Smeyers P, Raspall CM, Martínez BA, Ruiz FML, dkk. Use of benzodiazepines in prolonged seizures and status epilepticus in the community. An Pediatr (Barc) 2014;81:1-6.

20. Patel VF, Liu F, Brown MB. Advances in oral transmucosal drug delivery. J Control Release 2011;153:106-16.

21. Anderson GD, Saneto RP. Current oral and non-oral routes of anti-epileptic drug delivery. Adv Drug Deliv Rev 2012;64:911-8.

22. Scott RC, Besag FM, Neville BG. Buccal midazolam and rectal diazepam for treatment of prolonged seizures in childhood and adolescence: a randomised trial. Lancet 1999;353:623-6.

23. Mpimbaza A, Ndeezi G, Staedke S, Rosenthal PJ, Byarugaba J. Comparison of buccal midazolam with rectal diazepam in the treatment of prolonged seizures in Ugandan children: a randomized clinical trial. Pediatrics 2008;121:58-64.

24. Kutlu NO, Dogrul M, Yakinci C, Soylu H. Buccal midazolam for treatment of prolonged seizures in children. Brain Dev 2003;25:275-8.

25. Melendez R, Batista D, Font D, Bausha T, Hijano A, Rocha A, $\mathrm{dkk}$. Prolonged convulsions treated with buccal midazolam in a setting of mentally retarded patients with refractory epilepsy. Neurologia 2006;21:411-3. 